\title{
Conflits de culture et déviances des jeunes de banlieue
}

\section{François Sicot}

\section{(2) OpenEdition}

1 Journals

\section{Édition électronique}

URL : https://journals.openedition.org/remi/4168

DOI : $10.4000 /$ remi.4168

ISSN : $1777-5418$

Éditeur

Université de Poitiers

\section{Édition imprimée}

Date de publication : 1 octobre 2007

Pagination : 29-56

ISBN : 978-2-911627-46-6

ISSN : 0765-0752

\section{Référence électronique}

François Sicot, "Conflits de culture et déviances des jeunes de banlieue », Revue européenne des migrations internationales [En ligne], vol. 23 - $n^{\circ} 2$ | 2007, mis en ligne le 01 octobre 2010, consulté le 14 avril 2022. URL : http://journals.openedition.org/remi/4168; DOl : https://doi.org/10.4000/remi.4168

Ce document a été généré automatiquement le 14 avril 2022.

(c) Université de Poitiers 


\title{
Conflits de culture et déviances des jeunes de banlieue
}

\author{
François Sicot
}

1 Après une brève discussion des réticences des sociologues à prendre en compte l'ethnicité dans l'analyse de la déviance des jeunes d'origine étrangère des quartiers de relégation, on présentera quelques éléments de la théorie des conflits de culture élaborée dans les années 1930 aux États-Unis. On verra ensuite que c'est moins l'incompatibilité d'une culture avec la société française que sa disqualification qui peut expliquer les déviances. Enfin, on tentera d'établir que les conflits de culture qui peuvent se produire à l'intérieur des familles ont des conséquences sur le contrôle familial de la déviance, l'intégration normative.

\section{Déviance et ethnicité : des relations dangereuses}

2 Les émeutes de novembre 2005 sont venues consacrer la présence dans nombre de débats politiques, médiatiques, scientifiques de la question ethnique. Non que l'immigration n'ait pas été un thème constant de débats politiques et d'opinion. Mais plusieurs faits sont à noter. D'abord une libération de la parole raciste mais plus généralement des discours ethnicisants: un nombre toujours plus grand de phénomènes sont désormais considérés comme s'expliquant par l'origine nationale, culturelle des protagonistes. D'autre part, le mouvement social des Indigènes de la République, à l'opposé des aînés de la marche des Beurs, revendique à la fois le droit à la différence, un projet politique multiculturaliste et un droit d'inventaire par rapport à l'histoire coloniale française. Enfin au plan scientifique, un verrou semble avoir sauté : la prise en compte de l'ethnicité semble de plus en plus justifiée ${ }^{1}$ malgré les risques politiques et les difficultés techniques, méthodologiques qu'elle présente.

3 S'il est pourtant un domaine de la sociologie dans lequel le refus d'analyser les faits en termes d'ethnicité reste inchangé, c'est celui de la déviance et du crime. En effet, pour expliquer la déviance (juvénile), les sociologues recourent à la panoplie des théories classiques en les renouvelant, les articulant, mais en refusant pourtant d'user de la 
théorie dite des conflits de culture de Wirth (1931) et surtout de Sellin (1960). Deux raisons justifieraient cette mise au ban. La première est le réductionnisme culturaliste qui la caractériserait «avec lequel les sciences sociales ont mis longtemps à prendre leurs distances, en France comme aux États-Unis $»^{2}$. La seconde est qu'elle se focalise sur la dimension étiologique du crime au détriment des réactions sociales ${ }^{3}$ qu'il suscite c'est-à-dire la création des normes pénales, l'ordre juridique en tant qu'il est un élément de cette pensée d'État productrice des catégories au travers desquelles nous pensons l'immigration (voir Brion, 1997, 1998; Réa, 2001), l'activité de la police, le fonctionnement du système judiciaire.

4 Deux autres raisons nous semblent expliquer ce refus. L'une tient à l'histoire même de la sociologie criminelle. Dans un texte sur «le sociologue, la culture et le crime», P. Robert (1999: 33) rappelle que la rupture épistémologique qu'a dû accomplir la sociologie du crime a consisté à "ne plus penser le criminel comme différent des autres, cesser de traquer en lui le "penchant", la "prédisposition", la "dégénérescence", "la constitution morbide" [...]. L'enflure du débat sur les migrants compte probablement pour beaucoup dans cette difficulté : qu'ils soient européens - mais Latins, Slaves ou Juifs - Chicanos ou, pis encore, Asiatiques, on assure en tout cas qu'ils sont trop loin du modèle (W)hite (A)nglo (S)axon (P)rotestant originaire pour avoir quelque chance de se fondre dans le melting pot ".

5 La sociologie du crime repose donc en partie sur cette rupture avec le sens commun entre le criminel et le différent - dont la figure paradigmatique est le migrant - et ses avatars pseudo-scientifiques ${ }^{4}$. Mais si «le poids du débat sur l'immigration, la forte intolérance xénophobe entravent fort la rupture à opérer entre déviance et différence pour déployer une lecture sociologique du crime » (Robert, 1999: 33); ce poids pèse également sur les épaules des criminologues qui ne peuvent analyser sereinement les relations entre migration ou origine étrangère et criminalité. Car ces relations existent: l'opinion, une bonne partie de la classe politique pensent d'une certaine manière, que ces populations sont sur-délinquantes. Le sociologue peut tenter de réfuter cette liaison ou, autrement, en faire un élément du phénomène à étudier : des acteurs produisent un discours qui est constitutif de la réalité à la fois lorsqu'il donne lieu à - et justifie - des politiques migratoires, des incriminations pénales. C'est en faisant le lien entre différence et déviance ou délinquance, qu'une partie de la population intervient dans la régulation informelle de comportements, attitudes, expressions de ceux qu'elle classe comme "étrangers ". D'autre part, ces discours participent à la construction identitaire et à l'expérience de l'être en société des étrangers, des immigrés et de leurs enfants.

6 Enfin les sociologues qui étudient la délinquance et le crime n'échappent pas à la tentation du politiquement correct et au tabou de l'origine ${ }^{5}$ et le risque de se voir imposer sa problématique de l'extérieur, par les champs politiques, médiatiques, y est particulièrement fort. Ainsi, la liaison entre délinquance et immigration étant toujours plus présente dans les débats publics, les chercheurs se donnent souvent comme objectifs de déconstruire les préjugés, de réfuter l'existence d'un " problème immigré ", voire de démontrer l'apport positif de l'immigration à la nation française. Dans cette optique, la plupart des écrits sur la délinquance des jeunes de banlieue s'efforcent à la fois de montrer et d'analyser les discriminations dont ces jeunes sont victimes et d'affirmer que, si problème il y a, il est moins dans un manque d'intégration culturelle que d'intégration économique et sociale. On affirme que les jeunes sont intégrés 
culturellement ${ }^{6}$, qu'ils sont "quasiment assimilés ", qu' « ils sont des Français comme les autres ", sans apporter de preuves empiriques de la dite intégration culturelle à l'exception de l'idée qu'ils « partagent les valeurs de la société de consommation ». Sans que l'on sache non plus si tout ce qui constituait la culture originale des parents s'est évaporé à la génération suivante ou si ce qu'il en reste représente des reliquats négligeables et voués à l'extinction.

7 Malheureusement, cette insistance sur l'intégration culturelle aboutit à nous détourner des questions liées à l'hétéroculture des enfants de migrants, et les stratégies des uns et des autres, des enfants et de leurs parents pour produire une synthèse considérée comme acceptable ou supportable de cette double appartenance. L'affirmation de l'intégration culturelle conduit également à masquer la diversité des situations. C'est des enfants originaires du Maghreb et d'Afrique Noire dont il s'agit. Mais dira-t-on des jeunes nés de parents asiatiques qu'ils sont intégrés culturellement quand ils font le choix de vivre en communauté ? La discrétion est-elle un indicateur pertinent de l'intégration culturelle?

8 Dira t-on des Turcs, des Arméniens, des Portugais, des Juifs... qui ont une vie communautaire intense, qui se réfèrent à une histoire, à une culture commune, qui ont développé des instances communautaires parfois très organisées qui peuvent être reconnues par l'État-nation comme des instances représentatives qu'ils sont intégrés culturellement ?7 Et surtout que la déviance des jeunes de ces milieux est insignifiante ou que le type de rapport entre culture communautaire et culture majoritaire ne soulève aucun problème pour les jeunes qui y sont soumis ? ${ }^{8}$ À propos des Turcs en France, un auteur note qu'ils sont «très attachés à leur terre, très patriotes, mêmes chauvins [...], que prévaut également chez eux cette culture du «gurbet », cet état de l'exilé qui éprouve une perpétuelle nostalgie de sa terre quittée et garde en mémoire la promesse faite aux vieux et aux "pays » de rentrer, aussi intègre pur et fidèle aux traditions qu'au moment du départ. Les Turcs ont donc, dès le début des années 1980, commencé à spécifier leur présence, à délimiter leur territoire, à affirmer leur visibilité. Nul désir dans ce groupe de s'effacer» (Petek-Salom, in Dewitte, 1999). Or leurs enfants nés en France sont soumis à un contrôle communautaire et familial strict, des conflits avec les parents peuvent en résulter et se traduire par des ruptures ou des tentatives de suicide. Force est de constater que nous ne savons pas si ces conflits donnent lieu également à l'engagement dans la délinquance, que nous ne savons pas comment les membres de la communauté régulent les déviances des jeunes soumis à ces conflits de culture.

9 Le cas des Tsiganes est emblématique des difficultés que nous pose la thèse de l'intégration culturelle. Car les membres de cette population vivent en France dans des conditions extrêmement hétérogènes, les uns sont sédentaires les autres plus ou moins nomades, certains revendiquant une "tsiganité » quand les autres l'ignorent. Il paraîtrait dès lors périlleux d'opposer à la représentation ancestrale de la délinquance des Tsiganes qu'ils sont des Français comme les autres.

De l'autre côté si l'on peut dire, le chercheur qui prétend prendre en compte la dimension ethnique ou culturelle de certains comportements ou situations est rapidement accusé de trois travers. Le premier se nomme culturalisme et vise une définition de la culture comme ensemble homogène de caractéristiques, normes de vie, de conduites, valeurs, et l'assimilation de cette culture à un fait de nature 9 . Plus encore, la voie de la reconnaissance de différences culturelles peut sembler bien trop périlleuse 
pour être empruntée tant guette la chute dans le différencialisme et le néo-racisme (culturel $)^{10}$. Or les théories contemporaines ne se réfèrent plus à l'ethnie comme à un donné mais à l'ethnicité comme processus d'attribution, construction sociale. «Toute la problématique de l'ethnicité a consisté à rompre avec les définitions substantialistes des groupes ethniques, et à poser qu'une identité collective n'est jamais réductible à la possession d'un héritage culturel, fut-il réduit à un "noyau dur", mais se construit comme un système d'écarts et de différences par rapport à des autres significatifs dans un contexte historique et social déterminé » (Poutignat et Streiff-Fénart, 1995). De même est-il évident que la culture n'est pas un ensemble d'attributs acquis lors de la socialisation primaire, au sens des Patterns of culture de Kardiner, encore moins un état de seconde nature. Il convient donc de se demander sérieusement quelle part peut avoir la culture dans l'émergence de comportements déviants.

Le second écueil consisterait à ethniciser les relations sociales c'est-à-dire à privilégier une lecture des relations sociales qui met l'accent voire explique les phénomènes par les caractéristiques ethniques des populations observées. À rebours, ceux qui portent cette accusation subsument les différences culturelles et la catégorie ethnique sur ce qui leur semble compter vraiment: l'appartenance sociale, la relégation spatiale. Ethniciser, c'est en quelque sorte se tromper de lecture et, en l'occurrence, d'ennemi. L'ethnicisation serait un point de vue à déconstruire, à dénoncer.

12 Enfin, le refus de prendre en compte l'ethnicité ou la différence culturelle dans l'explication de la déviance des jeunes de banlieue s'origine dans un refus de ce qui constituerait une valorisation du communautarisme considéré comme le chancre de la République française et de sa conception des citoyens, tous égaux, quelle que soit leur origine. Que l'on évoque comme Bastenier un "nationalisme méthodologique » ou comme Lorcerie «l'ethnonationalisme» (orientation ethnique du nationalisme), avec Hajjat le «nationalisme républicain » des sociologues ou avec Manço une « conception normativiste de l'intégration » (lorsque l'intégration est synonyme de disparition de la culture des immigrés ou de leurs enfants), il y a toujours le même biais que l'on pourrait aussi bien dire d'anti-racisme au nom de l'universalisme républicain dans ces appréhensions de la déviance des jeunes.

13 Lorsqu'elle est reconnue, la revendication ethnique des jeunes est conçue comme l'action des seuls relégués et une forme d'action essentiellement réactive à leur exclusion des bénéfices de la modernité. La revendication de sa différence, d'une origine, d'une tradition est interprétée comme des replis dus à l'incapacité à accéder à la modernité. Il s'agirait d'aveuglements sur la véritable aliénation subie avec l'idée que, une fois leur position économique assurée, les revendications identitaires devraient disparaître. Se libérer, c'est se libérer de sa culture et rejoindre l'universel incarné par le modèle français de la citoyenneté.

Plutôt que de partir de l'hypothèse que les étrangers et les populations d'origine étrangère ne sont pas plus délinquants ou déviants que le reste de la population, il peut toutefois être tout à fait heuristique de faire l'hypothèse inverse : qu'est-ce qui pourrait faire que certains commettent plus d'actes déviants que les autres? Ou mieux, le sens des délits est-il le même lorsqu'ils sont commis par des jeunes d'origine étrangère non stigmatisés, des jeunes des quartiers de relégation, des jeunes nés de parents français? Autrement dit, distinguer dans l'analyse les notions et le contenu de ces faits que sont la culture, l'ethnicité, l'immigration, la relégation. 
Les analyses qui suivent sont fondées empiriquement sur plusieurs recherches menées sur le quartier du Mirail à Toulouse ; une relative familiarité avec ce terrain et surtout, ce qui semble ici plus qu'ailleurs une posture méthodologique indispensable, le croisement des sources et des méthodes. Nos terrains sur ce quartier ont débuté en 1999 avec une enquête ethnographique sur la délinquance. Pendant dix-huit mois, nous avons accompagné des jeunes dans des activités sportives et effectué du soutien scolaire, nous avons été présent auprès de militants, participé à des activités dans deux associations ${ }^{11}$, «traîné " sur le quartier, passant du temps à discuter de rien et de pas grand-chose avec les uns et les autres, réalisant également une dizaine d'entretiens approfondis. Ultérieurement, une trentaine d'entretiens portant sur la question de la transmission de la culture ont été menés avec des étudiants, d'origine culturelle, de genre, géographique (quartier de relégation ou non) et sociale très diverses ${ }^{12}$. Deux autres recherches sur la déscolarisation et sur les Centres Éducatifs Renforcés (CER) nous ont conduit à poursuivre la fréquentation du Mirail et des jeunes qui y résident. Enfin, la fréquentation épisodique d'une salle de sport permet de garder un contact avec le quartier. Par sources empiriques, il faut donc entendre cette présence physique sur le quartier, auprès des jeunes et des adultes, des entretiens formels et des discussions, des observations via la participation à des activités mais aussi la lecture de dossiers judiciaires et médico-sociaux, la participation à un ensemble de réunions professionnelles où la déviance des jeunes est discutée et traitée. La prégnance de la question de l'ethnicité provient de cet ancrage empirique et non d'un choix théorique ou idéologique a priori. Lors des émeutes consécutives à la mort du jeune Habib tué par un policier au Mirail fin 1999, nombre de témoins ont ainsi été interpellés par des jeunes : « On est des Arabes et vous les Français, on va vous niquer $! »^{13}$.

\section{La théorie des conflits de culture de Sellin et son actualité}

Les thèses psychosociales relatives à notre sujet sont désormais bien connues. Elles montrent que les jeunes placés dans des situations interculturelles sont nécessairement confrontés à un dilemme identitaire lié à leur double appartenance culturelle ${ }^{14}$. Ce dilemme pouvant se traduire de manières différentes, dans des stratégies identitaires, l'engagement dans la délinquance, des pratiques à risque, des souffrances voire des pathologies. Le sociologue américain T. Sellin a quant à lui développé dès 1938 une théorie dite des conflits de culture qui reste ignorée ${ }^{15}$ lorsqu'elle n'est pas condamnée pour déviation culturaliste. Elle est pourtant d'une très grande actualité pour les sociétés contemporaines qui comme la société française se multiculturalisent, les conflits de culture étant des excroissances des processus de différenciation sociale. Elle permet également de dépasser les analyses qui ne voient dans la délinquance des jeunes des minorités ethniques que la résultante des discriminations et du racisme subis ${ }^{16}$ pour replacer les phénomènes dans l'ensemble plus vaste de la dynamique culturelle des rapports sociaux.

Sellin invente cette notion de conflits de culture en 1938 et la reprendra dans deux conférences publiées en 1960. Il développe sa théorie à la fois sous l'angle du passage à l'acte et sous l'angle de la réaction sociale pénale. "Je me propose - écrit Sellin d'employer le terme "conflit culturel" pour désigner la lutte entre des valeurs morales ou des normes de conduite opposées ou en désaccord» $(1960: 815)$. 
18 La définition des crimes est culturelle. Ainsi dans certaines cultures considère-t-on comme normal de venger l'honneur bafoué dans le sang alors que d'autres prohibent toute atteinte violente à l'intégrité physique d'autrui. Mais le droit pénal ne reflète pas la culture d'une société parce que la diversité culturelle est inhérente à toute société, ne serait-ce que par la présence de groupes sociaux ayant leurs valeurs et leurs normes. Le droit pénal est un ensemble de règles qui dépend des normes et des valeurs du ou des groupes dominants et des intérêts des groupes les plus influents. Lorsque Sellin écrit qu'un «manque de conformité entre les lois d'État et les idées morales de différents groupes sociaux à l'intérieur de la population peut être observé partout où les règles de vie des groupes dominants diffèrent de celles des groupes assujettis ou dociles » $(1938: 22)^{17}$; on comprend qu'un pays peut, par ses choix législatifs, participer à la production de plus ou moins de criminalité - au sens ici de criminalisation - des groupes minoritaires.

19 C'est par rapport à une culture dominante que sont définies des transgressions et celles qui doivent faire l'objet d'une sanction pénale. En édifiant des normes pénales, une société peut se montrer plus ou moins tolérante à la diversité culturelle. À l'aune des débats contemporains sur le multiculturalisme, on voit bien que la question est de savoir comment la loi peut incorporer ou non des règles qui ne découlent pas seulement de la culture des groupes dominants mais qui respectent aussi les valeurs des minorités culturelles. La criminalisation primaire - l'inscription dans la loi de crimes - peut concerner directement des minorités culturelles en condamnant des pratiques dites traditionnelles ou indirectement quand les publics visés par une loi s'appliqueront de fait essentiellement aux individus d'origine étrangère ${ }^{18}$. La prétention d'une culture dominante au monopole de l'universel peut ainsi aboutir à la criminalisation primaire de règles, de coutumes, de manières de faire des membres des cultures dominées.

20 Par la socialisation familiale, nous acquérons les éléments de traditions culturelles de notre famille, des concepts du bien et du mal. Par nos contacts avec l'extérieur, nous rencontrons progressivement d'autres normes. C'est au travers des diverses expériences vécues dans les groupes sociaux auxquels nous participons que se constitue notre système de normes, de valeurs. Selon Sellin, quelles que soient les sociétés, les individus ne sont jamais des représentants d'une Culture préservée de mélanges, emprunts. Tous les individus sont membres de plusieurs groupes et donc potentiellement se partagent entre plusieurs cultures. Or entre les groupes, il y a des normes communes et d'autres en désaccord. Chaque groupe est normatif. La question est de savoir si 1. Ces normes s'opposent ; 2. Si les individus dans ce cas sont capables de faire une hiérarchie, comment ils s'orientent. Autrement dit aussi, quelle est l'autorité de cette norme qu'est la loi (pénale)?

21 Si donc les conflits de culture sont inhérents à toute société, un phénomène social normal, ils peuvent s'accroître au contact de cultures nationales, dans l'immigration ou la colonisation ${ }^{19}$ et avec la diversification culturelle des sociétés modernes. "Plus une culture devient complexe, plus il devient vraisemblable que le nombre des groupes normatifs qui influent sur l'individu sera important et que feront défaut les chances que les normes de ces groupes soient uniformes, même si elles se chevauchent en raison d'une acceptation commune de certaines normes » (1938:29). Or, contrairement à l'idée qui voudrait que la dimension culturelle de l'action, les revendications identitaires et d'appartenance constituent un repli communautaire - voire tribal -, un 
archaïsme par peur de la modernité, la modernité pourrait bien être au contraire caractérisée par un éclatement des États-nations qui se donnaient à voir comme culturellement homogènes.

Si l'on s'en tient maintenant aux développements étiologiques de la théorie de Sellin, trois éléments nous semblent pertinents pour comprendre les phénomènes actuels : les conflits de cultures sont des rapports sociaux et ceci entre cultures, générations et classes sociales; la relégation spatiale génère de ces conflits; les conflits de culture sont aussi intra-familiaux et psychiques.

Il y a dans toute société, potentiellement, un décalage entre des normes, des conduites anciennes et un code nouveau. À l'inverse, les mœurs et les pratiques prescrites peuvent anticiper sur une évolution du droit. Si les cultures varient dans le temps cela signifie que les conflits générationnels sont aussi en partie des conflits culturels: les jeunes ne partagent pas l'ensemble des valeurs des adultes et leur définition des bonnes manières d'agir, des buts légitimes à atteindre peuvent s'en distinguer notablement. Or une partie du phénomène social qui nous occupe concerne des jeunes potentiellement en conflit avec les adultes du voisinage ou leurs parents du fait de décalages culturels d'origine générationnelle. Exemplaire de ce point de vue, le quartier du Mirail où nous menons nos observations se caractérise par une forte proportion de jeunes ( $48 \%$ des habitants ont moins de 25 ans) et de personnes âgées (les 75 ans et plus représentent $21,5 \%$ de l'ensemble).

Sellin d'autre part ne réduit pas ses analyses à la confrontation de personnes ou groupes d'origine nationale, géographique diverses, il inclut ce qu'on appellerait autrement des rapports sociaux de classes : «la conduite dite moralement mauvaise varie non seulement d'une culture à l'autre mais aussi au sein de la même culture - État ou nation - où nous ne trouvons pas une uniformité complète à ce sujet parmi les groupes sociaux qui la composent. Ceci conduit inévitablement à des situations dans lesquelles l'individu qui obéit à une norme acceptée par son groupe ou par l'un des groupes dont il fait partie, se trouve en train de violer d'autres normes qu'il peut connaître ou ne pas connaître, selon l'étendue et la portée de ses appartenances à d'autres groupes» (1960: 832). Le conflit de culture n'est pas à entendre nécessairement entre "ethnies» différentes mais aussi entre milieux sociaux. Sellin cite pêle-mêle des exemples où des groupes aux cultures étrangères l'une à l'autre se rencontrent ; le cas le plus typique étant celui de la colonisation. Mais il cite aussi des groupes sociaux et de génération, qui ont des sous-cultures différentes.

Enfin, c'est par son organisation spatiale qu'un pays peut favoriser ou au contraire limiter les conflits de culture. En effet, si nous ingérons des éléments de traditions culturelles, des conceptions du bien et du mal, de la justice, de l'ordre social par la socialisation familiale, la rencontre avec d'autres groupes sociaux nous porte à la relativisation et à l'intégration d'un système de valeurs qui transcende les particularismes. La ségrégation, la ghettoïsation vont conduire à une socialisation au sein de la seule culture des membres rencontrés à proximité, qu'il s'agisse d'éléments liés au pays d'origine des adultes présents ou de la sous-culture des rues des groupes de pairs. Or avec d'autres sociologues enquêtant sur divers quartiers relégués, nous avons $\mathrm{pu}$ constater combien les jeunes font l'expérience de grandir à part, entre eux, sans guère rencontrer les « Français ".

Les conflits de culture sont donc indissolublement des rapports sociaux de génération, de classe et pays d'origine ${ }^{20}$ amplifiés par le phénomène de la relégation. On trouve une 
excellente preuve de l'actualité de cette théorie dans un passage de Sellin qui cite une recherche publiée en 1953 sur les expériences d'adolescents des quartiers pauvres et des classes moyennes. À propos des premiers, il note :

"Ils étaient membres d'un club de jeunesse et avaient été, pour la plupart, une fois ou à diverses reprises expulsés de clubs similaires du quartier, parce qu'ils se battaient souvent, détruisaient le matériel du club, et ainsi de suite ». Le rapport de recherche disait: "cette façon de faire des blagues est nettement un type sous-culturel de conduite; jusqu'à ce que les garçons entrent à l'armée, on tolère chez eux n'importe quelle conduite s'ils déclarent qu'ils le font "à la blague". Cette expression couvre toutes sortes de comportements, depuis le fait de piquer quelqu'un avec une épingle jusqu'au vol et à la destruction d'objets [...]. Les garçons et les filles, quoique celles-ci s'adonnent moins aux blagues, sont tout à fait incapables de comprendre le point de vue de la personne dont la propriété a été détruite ou volée ; personne ne doit se sentir coupable ni avoir besoin de s'excuser, après tout, c'était une blague. Cette absence de sentiment de culpabilité est frappante. Rien n'est regretté, à moins que la chose est découverte et prouvée à charge de l'auteur et, par conséquent, punie [...]. Les jeunes gens ne reconnaissent jamais qu'ils sont dans leur tort. Tout ce qu'ils font, ils peuvent le nier, se justifier ou déclarer avec défi que ce n'était que pour rire [...]. On les suspend du club pour une semaine ou un mois; ils reviennent subrepticement et donnent des coups de couteau dans le drap du billard. Lorsqu'ils sont réadmis au club, ils se plaignent de ce que celui-ci n'offre pas de distractions suffisantes et indiquent comme preuve que le billard est inemployable. Ni eux, ni les autres membres du club ne considèrent le billard endommagé comme un résultat de leur propre comportement; il est pour eux la preuve que le club cherche à faire échouer leur désir de s'amuser ».

Ce que nous observons aujourd'hui dans les quartiers d'habitat social n'a apparemment rien de bien nouveau: c'est un phénomène étroitement associé à la ségrégation des groupes sociaux, à l'absence de mixité sociale et/ou ethnique. Certes toute société est hiérarchisée et des groupes sociaux, ou de genre ou ethniques, sont toujours relativement séparés, vivant des expériences différentes ou résidant en des lieux séparés. Mais dans les sociétés modernes où la séparation des groupes est aggravée par l'absence de régulation de leurs échanges, les conflits, de valeurs, de normes, deviennent normaux.

\section{Ethnicité et culture des jeunes d'origine étrangère... et des autres}

Avant d'envisager comment la culture des jeunes, leur ethnicité peuvent expliquer la déviance, il convient d'éclaircir ce que l'on peut entendre par culture, en quoi des éléments de la culture d'origine sont constitutifs de l'ethnicité.

\section{Ethnicité et culture}

Une lecture trop rapide des théories contemporaines de l'ethnicité pourrait en faire une pure construction sociale sans contenu objectif. Or la culture est le fond objectif qui spécifie l'ethnicité. Elle est pour Barth "l'instrument par lequel des groupements humains engagés dans des rivalités ou des luttes sociales cherchent à manifester symboliquement leurs frontières, c'est-à-dire leur existence collective qu'ils configurent en l'organisant dans des identités et des appartenances ». L'ethnicité est "l'organisation sociale de la différence culturelle ». La culture doit être analysée dans son contenu et dans la mobilisation qu'en font les acteurs, ceux qui en sont porteurs et ceux qui l'attribuent aux autres. L'acteur ethnique use de la culture objective mais 
l'anime aussi d'un sens subjectif. Dans les termes de D. Juteau (1999) qui articule les dimensions objectives et subjectives de l'ethnicité, il y a une face interne et une face externe des frontières ethniques. L'ethnicité c'est tout à la fois la culture spécifique que nous possédons tous et une caractéristique attribuée par le majoritaire au minoritaire. Autrement dit, on peut hériter culturellement - on ne peut qu'hériter culturellement - sans qu'il y ait formation d'une conscience ou d'un groupe ethnique.

Les mères d'origine asiatique, latine, maghrébine, d'Afrique subsaharienne, d'Europe de l'Est, de France apprennent quotidiennement à leurs enfants à se vêtir, manger, jouer, marcher - tout un rapport au corps. Elles transmettent une langue, une religion, un style de vie, des valeurs, des manières de faire et de penser. Le style éducatif qu'elles emploient est tout à la fois contenu et forme de la relation, moyen culturel de cette transmission. Elles forment des individus au travers d'une culture. Il n'y a pas d'humanisation, de socialisation sans inculcation d'une culture particulière. Des individus porteurs d'une culture, tel est donc notre point de départ.

La culture d'un groupe n'est jamais une culture originelle, elle est travaillée par les contacts, les emprunts, par la volonté des acteurs. Dans le cas particulier de la migration se produit un choc des valeurs, des cultures; il y a rupture. Le cadre culturel nouveau de la société d'accueil produit une influence sur les migrants, ce qui interdit toute reproduction à l'identique, des parents aux enfants, de la culture du pays d'origine. Et cela même si les parents en avaient la volontée ${ }^{21}$. En particulier, les parents ont à faire face à des enfants qui introduisent dans la sphère privée des valeurs, des désirs, des volontés qui lui étaient étrangers jusqu'alors ${ }^{22}$.

À l'inverse, la rupture totale des enfants vis-à-vis de la culture des parents est impossible. Quel que soit donc le projet des parents en ce qui concerne la transmission, schématiquement transmettre le plus possible ou au contraire minorer son histoire et ses valeurs en vue de faciliter l'intégration des enfants, il n'y a que des variations autour du principe général de la continuité généalogique avec les parents et de l'influence de la société d'accueil, le croisement entre la culture du pays d'origine et la socialisation dans le pays d'accueil: emprunts, fécondations mutuelles. Ce qui est évident si l'on sait que la transmission de la culture s'opère pour l'essentiel en dehors de toute volonté explicite, par imprégnation, dans les échanges communicationnels ou autres, dans les pratiques de la vie quotidienne. La culture des parents est toujours nécessairement là et elle constitue un pôle de structuration psychique essentiel pour l'enfant ${ }^{23}$.

33 Si tous les individus héritent d'une culture, cette éducation n'aboutit nécessairement ni à des communautés ni à des groupes ethniques. Les individus qui appartiennent à des groupes qui revendiquent une histoire, la conviction de participer à une tradition, des valeurs culturelles particulières, réelles ou imaginaires, un entre-soi, qui développent des stratégies résidentielles pour les maintenir forment une communauté. Elle se donne pour projet de préserver une culture dite traditionnelle et des liens sociaux affinitaires entre ses membres. Par contre, le groupe ethnique peut partager ce même sentiment d'une originalité culturelle ou de destin mais il se voit surtout attribuer ses caractéristiques et ses contours par le groupe majoritaire. Il subit son assignation à une communautée ${ }^{24}$.

34 L'existence d'une culture originale, distincte de la culture majoritaire a peu à voir avec le caractère récent de la migration. Contrairement à l'idée qui voudrait que quelque chose comme l'intégration définie par l'absence de traits particuliers se réalise 
naturellement avec la succession des générations - les immigrés s'intégreront avec le temps et deviendront finalement des Français comme les autres ${ }^{25}$ - les individus peuvent choisir la communalisation ou se voir imposer des attributs ethniques.

Les différences culturelles n'ont pas de sens en soi. C'est moins une distance culturelle objective qui pourrait empêcher la cohésion sociale, faire problème - aux jeunes qui doivent s'en débrouiller ou au groupe majoritaire et à ses institutions - que le rapport de la culture particulière à la culture majoritaire, le vécu de son propre héritage culturel.

\section{L'expérience d'une culture reléguée}

La culture des groupes ethniques est une culture dépréciée, reléguée objectivement et subjectivement. Si la catégorisation ethnique est un processus subjectif, la production des ethnicités est également le résultat de politiques. En effet, les politiques d'attribution de logements - qu'on peut qualifier de production institutionnelle d'ethnicité - par exemple participent au regroupement des populations sur des bases communautaires et par contre-coup à : 1 . La perpétuation d'un entre-soi $\operatorname{subi}^{26}$, de références à la culture d'origine de manière "mécanique » c'est-à-dire sans qu'il y ait même volonté en ce sens ; 2 . La conscientisation de soi-même comme a. étranger et, indissolublement comme b. membre d'une minorité reléguée ; 3 . La représentation par les autres des Arabes $^{27}$ comme un tout auquel on attribue toutes les caractéristiques négatives du quartier. Plus généralement les institutions, les acteurs collectifs, moraux (entreprises, services publics...) produisent de l'ethnicité en ce double sens morphologique et de subjectivation.

Le conflit de culture peut-être une cause de déviance si la culture des individus est dévalorisée et que cette dévalorisation non seulement provoque une tension psychique mais est vécue comme une injustice. C'est pourquoi, outre les émeutes, une part du sens des déviances et des délits tels que dégradations, deals, vols réside également dans le sentiment d'être discriminé pour ses origines culturelles. Ce sentiment donne lieu à une neutralisation des normes morales dominantes ainsi qu'à l'affirmation d'un «nous » opposé à « eux ». ${ }^{28}$ Voler n'est pas seulement s'approprier un bien désirable, c'est aussi se venger.

S'il est vrai que les jeunes des quartiers de relégation sont pour la plupart français, on ne peut pas en conclure qu'ils sont des Français comme les autres ${ }^{29}$. Or le quartier ethnique est, par définition, lieu de revitalisation, de reproduction d'une originalité culturelle. D'autant plus que malgré la volonté politique de mettre fin à l'immigration - ou plutôt à une mauvaise immigration, celle des pauvres - la France, et particulièrement ses quartiers d'habitat social, continue à recevoir un apport légal ou non de populations qui migrent de l'Afrique ou d'autres aires paupérisées du monde. Affirmer qu'ils sont des Français comme les autres ne correspond donc à aucune réalité. Les jeunes eux-mêmes introduisent des distinctions culturelles dans leurs relations. Les «blédards", ceux qui arrivent dans le quartier en provenance du Maghreb, sont « vannés » par les natifs du quartier : le bled, c'est le pays arriéré où « il n'y a même pas l'électricité ou l'eau courante ». On se moque de l'accent du pays et du français mal maîtrisé, des fringues ringardes.

Dans le même temps, les arrivants de l'étranger vont vivifier, entretenir la présence de cultures, de valeurs, de manière de vivre, de penser et de faire du Maghreb, de l'Afrique 
noire. Les circulations, les mobilités transnationales, précisément décrites par A. Tarrius (2001) et qui ne concernent pas seulement des biens, des marchandises mais aussi des symboles entretiennent ou reproduisent des liens. La présence sur les marchés des produits venus des pays d'origine, des ouvrages ou des cassettes de musique, de littérature étrangère, des produits dérivés de la religion, la présence au foyer des télévisions étrangères, les associations où se retrouvent les vieux, la langue parlée par les parents, les vacances au pays ${ }^{30} \ldots$ On n'en finirait pas de relever tous ces éléments qui assurent la perpétuation de la présence de la culture des pays d'origine dans ces quartiers et sa participation à la production d'identités culturellement complexes.

Les jeunes d'origine maghrébine et d'Afrique noire des quartiers de relégation constituent ce que Sayad appelait une génération; "une classe particulière de conditions sociales engendre une classe particulière d'individus porteurs de caractéristiques qui leur confère une certaine unité et, à travers eux, une classe particulière de comportements qui leur sont propres dans la situation où ils sont placés » (1994: 159). En bref, ces jeunes font l'expérience d'une culture commune mais reléguée. En retour, ils vont se réapproprier cette culture en la valorisant et en la dotant d'éléments choisis qui permettent d'interpréter la situation présente. Ils vont, comme d'autres groupes, se doter d'une histoire commune. Histoire de la colonisation et histoire présente des discriminations. Les injustices subies par les uns deviennent les injustices constitutives du groupe. Pour autant, cette réappropriation n'est pas nous semble-t-il simplement un moyen de compenser une appartenance sociale dévalorisée. Elle est constitutive d'une identité moderne, caractéristique des sociétés multiculturelles où les anciennes appartenances sociales se sont défaites ${ }^{31}$.

Qu'en est-il des jeunes des autres minorités culturelles des quartiers de relégation? D'abord on doit constater qu'ils sont peu nombreux. Pour nous en tenir au quartier que nous connaissons, les immigrants d'origine latine ou leurs enfants ont progressivement été s'installer hors du Mirail ou ont accédé à la copropriété aux abords du quartier. D'autre part, loin de l'opinion commune qui voit dans les quartiers d'habitat social des unités indifférenciées, par le jeu des différents acteurs - habitants, bailleurs, édiles une distribution des populations sur base ethnique s'est opérée. Au Mirail, les rares populations d'origine asiatique sont ainsi regroupées dans quelques immeubles, les noirs africains dans d'autres alors que des barres d'immeubles accueillent plus de $90 \%$ de locataires d'origine maghrébine. Quant aux Espagnols désormais très peu représentés, ils se concentrent dans des copropriétés ${ }^{32}$ séparées des HLM par un grand boulevard. Après une discussion avec Saïd, je lui explique que je vais enquêter du côté des copropriétés, il me fait remarquer, sourire en coin : "Tu vas chez les fromages ». Lors des moments de tension sur les quartiers, particulièrement les émeutes, des groupes ethniques ainsi constitués objectivement et subjectivement en viennent alors à s'opposer, par voie de récriminations, pétitions voire en viennent à des confrontations physiques $^{33}$.

42 Les jeunes des minorités espagnoles, asiatiques ou autres se retrouvent de fait minoritaires parmi une majorité de jeunes issus de l'immigration africaine, avant tout d'Afrique du Nord. Plusieurs situations sont alors observables. Des familles qui souhaitaient éviter à leurs enfants la promiscuité juvénile du quartier ont fait le choix de le quitter. D'autres qui n'ont pu se le permettre se sont donc regroupées sur des espaces bien délimités. Certaines familles font tout pour éviter les contacts jugés 
délétères: leurs enfants ont alors toutes leurs activités - scolaires, associatives, sociabilités amicales - en dehors. Pour ces jeunes, la cité est une cité-dortoir.

Une hypothèse culturelle devrait être étudiée sérieusement: on évoque parfois une culture méditerranéenne qui expliquerait la présence si manifeste des jeunes sur les lieux publics ${ }^{34}$. À l'opposé, la culture asiatique en France se caractériserait par un repli sur la sphère privée et la recherche de la discrétion. Une telle conception de la bonne conduite pourrait alors expliquer la faible visibilité des jeunes asiatiques dans les groupes juvéniles dans les cités ${ }^{35}$. Pour autant, cette hypothèse ne pourrait concerner que certaines des minorités culturelles.

Restent qu'une partie des jeunes portugais, yougoslaves partagent l'ensemble des conditions de vie des Maghrébins et des Blacks majoritaires. Leurs sociabilités, leurs déviances sont alors tout à fait identiques. On peut d'ailleurs les remarquer dans les bandes. Rien dans leurs pratiques ne les distingue des autres. Comme eux, ils sont plus ou moins engagés dans les émeutes, les incivilités, les petits délits, le deal.

45 À l'intérieur des groupes juvéniles, les frontières ethniques sont manipulées en fonction des contextes. De la même manière que les Algériens s'affirment différents des Marocains à l'occasion d'un conflit de voisinage ou d'un match de football ou qu'ils se disent Maghrébins ou Arabes, semblables aux Marocains et aux Tunisiens; les Portos, les Chinetoques sont soit des membres du groupe de la cité à part entière et victimes comme les autres de la domination ethnique et sociale, soit ils sont singularisés. Dans la salle de sport, les Blacks pratiquent ensemble et se croisent autant qu'ils se mélangent avec les Maghrébins. Les vannes ethniques font partie du registre ludique courant. Mais dans la confrontation avec la BAC (Brigade Anti-Criminalité), dans l'opposition aux autres quartiers, c'est le nous qui l'emporte.

Les conflits de culture ne sont donc pas absents des sociabilités juvéniles mais ils dépendent à la fois des contextes locaux qui produisent des arrangements de voisinage, des stratégies familiales et des situations. De même n'est-il pas exclu que des conflits interethniques entre groupes de jeunes adviennent, entendus non pas comme résultant d'une distance culturelle objective mais d'une mobilisation par les acteurs du registre d'action culturel dans un contexte social et politique particulier.

\section{Conflits de culture dans la sphère privée}

En discutant de l'américanisation des jeunes nés de parents ayant migré et de ce qui fait qu'ils se détachent du contrôle parental, Sellin nous introduit à une autre dimension des conflits culturels : ils traversent la sphère familiale et soulèvent la question du contrôle familial de la déviance. "Le sort des fils et filles de certains immigrés est un sort difficile. Ils se trouvent dans une situation marginale, incapables d'accepter la culture de leurs parents parce qu'elle est inadaptée à leur vie, et néanmoins ils ne peuvent pas être acceptés par les représentants de la culture américaine. Ceci pourrait expliquer la proportion excessive des délinquants dans la première génération de ceux qui sont nés en Amérique » (1960: 102). Aujourd'hui sur le terrain, les travailleurs sociaux n'ont de cesse d'évoquer des dysfonctionnements familiaux, «l'invalidation du père ", l'absence de contrôle sur les enfants. Plutôt que de rejeter ces questionnements et arguments, on peut tenter de prendre au sérieux le savoir pratique des professionnels. 


\section{Conflits culturels et générationnels dans la famille} familiale et la volonté d'émancipation, entre adhésion et rejet ${ }^{36}$. La transmission de la culture du pays d'origine doit ainsi être considérée comme autre chose qu'une affaire politique ou un enjeu social : elle est au cœur des relations parents-enfants. Au-delà de la diversité des jeunes que nous avons rencontrés lors de nos travaux, jeunes connus de la justice pour avoir commis des délits, jeunes suivis par le secteur médico-éducatif, ou jeunes «tout venant » des quartiers de relégation, leur trait commun est la nécessité dans laquelle ils se trouvent d'avoir à construire leur identité sur des fondements incertains, changeants.

enstitue évidemment une période charnière, qui se traduit pour cette génération par des questionnements importants relativement à l'origine. C'est l'âge où de nombreux garçons disent s'être intéressés de près à la religion musulmane, avoir lu le Coran, en avoir suivi un certain nombre de préceptes. On sait que les jeunes de cette génération se fabriquent une conception de la religion tout à fait originale, bricolant avec des connaissances, des fantasmes, se permettant des accommodements. Mais ce n'est là qu'un cas particulier de cette invention d'une culture propre ${ }^{37}$. C'est l'âge où l'on choisit d'apprendre la langue arabe, où l'on souhaite aller au bled, rencontrer la famille restée là-bas. C'est la construction de l'identité donc la quête des origines. Pour cette génération, les arrangements avec les valeurs des parents font l'objet de réflexions, de décisions, de partages entre ce qu'on reçoit d'ici et de «là-bas ». Nombre d'enfants d'immigrés sont pris dans un rapport ambivalent au pays d'origine, à ceux qui en arrivent, à leurs parents dont ils peuvent dédaigner les valeurs, qu'ils peuvent mépriser pour avoir accepté leur situation, l'exploitation, leur absence d'ambition ou de révolte, leur mauvaise maîtrise de la langue; dont ils peuvent rejeter le modèle éducatif. D'un autre côté, ils disent leur admiration pour tout ce qu'ils ont subi, leur respect des valeurs qu'ils enseignent. Les fréquentations, les frustrations, les succès vont jouer un rôle considérable dans les orientations identitaires futures.

Loin des schémas simplistes tradition vs modernité, reproduction vs rupture, les enfants comme les parents opèrent chacun de leur côté des ajustements, ils se rencontrent dans la même incertitude et c'est ensemble qu'ils élaborent la transmission et non dans la confrontation de deux « modèles ». Rejeter ou simplement prendre de la distance avec la culture de ses parents c'est courir le risque d'un rejet réciproque. Pour un enfant, prendre parti pour l'école, ses valeurs, l'histoire qu'elle raconte, la mémoire qu'elle construit peut être vécu comme une trahison des parents, de ses origines. De la même manière qu'une enfant des classes populaires peut vivre comme une trahison ou un arrachement son adhésion à la culture cultivée de l'école. L'attachement à la culture d'origine est attachement aux parents qui la portent. N. Guénif-Souilamas décrit ainsi pour les filles d'origine maghrébine la difficulté à se construire "entre la nécessaire appartenance à une lignée, une généalogie qui inscrit dans la succession des générations et y confère une place unique à chaque individu et l'appartenance à une société qu'elles peuvent contribuer à forger et à transformer, pour autant qu'on leur en laisse la chance » $(2003: 154)^{38}$. À propos des filles toujours, Born remarque que «la situation la plus conflictuelle est celle où des jeunes filles sont réfractaires à la culture d'origine de leurs parents qui ont eux-mêmes des difficultés d'adaptation à la société 
d'accueil. Les parents ont, dans ce cas, une forte probabilité de réagir de manière rigide et violente aux tentatives d'émancipation de la jeune fille » $(2005: 42)^{39}$.

51 La transmission culturelle en situation d'acculturation ne donne évidemment pas nécessairement lieu à des conflits, encore moins à de la violence intra-familiale ou à de la délinquance mais dans tous les cas, elle requiert pour les enfants un intense travail d'intégration normative.

52 Les complications de la transmission peuvent peser sur la santé mentale des jeunes, produire des comportements scolaires inadaptés (Sicot, 2003), générer sur le plan psycho-social des souffrances ${ }^{40}$, du stress, de l'agressivité, du ressentiment ${ }^{41}$ ou encore des conflits entre membres de la famille. Ces conflits eux-mêmes peuvent être plus ou moins violents, se traduire différemment. Soit par une absence de dialogue, d'échanges, parce qu'on n'a rien à se dire, à partager, ou pour éviter d'envenimer les relations, soit par la violence, ou le rejet hors du domicile familial. Ce qui est le cas des pères qui préfèrent quitter le domicile familial lorsqu'ils ne peuvent plus faire face aux conflits ou de tous ces jeunes, mineurs parfois, qui sont mis dehors par leurs pères ${ }^{42}$. Un certain nombre de jeunes qui commettent des délits ont ainsi été exclus du domicile familial et squattent ou survivent dans les caves, grâce aux copains et à la débrouille ${ }^{43}$.

53 Un dernier élément, structurel, doit être pris en compte pour expliquer la déstabilisation du milieu éducatif : l'installation en France n'exclut pas la poursuite de la mobilité c'est-à-dire les retours plus ou moins longs et répétés des pères au pays, une cohésion de la famille compliquée par les déplacements successifs des uns et des autres (expulsion d'un des membres, arrivées échelonnées, mariage ici non reconnu là-bas...). On voudrait citer quelques exemples tirés de dossiers judiciaires ou médico-sociaux qui illustrent ces complications :

La mère de Fouad vit à Alger jusqu'à son divorce. Elle arrive en France, se remarie. Fouad vient la rejoindre "à contrecœur » alors qu'il a 15 ans. Il ne sait ni lire ni écrire le français et est rapidement orienté en EREA [Établissements Régionaux d'Enseignement Adapté]. $\mathrm{Au}$ début, il exprime le souhait de rejoindre sa famille en Algérie, puis il s'intègre au quartier. Fouad a un comportement de plus en plus déviant, sa mère fait une tentative de suicide à cause du comportement de son fils. Un éducateur note d'ailleurs que "la transplantation culturelle a été mal vécue ».

Le père d'Aziz, de nationalité algérienne, a été expulsé de France. Son fils n'a plus de contacts avec lui. La mère, de nationalité française, a eu sept enfants avec trois hommes. L'éducateur note : " absence totale d'autorité de la mère ».

La mère de Slimane est décédée lorsqu'il était enfant. Il vit avec son père qui ne veut pas de placement; "qu'est-ce que je vais devenir tout seul?». Si son fils commet de nouveaux délits, le père l'a menacé d'un retour au Maroc.

Le père d'Isham est ouvrier agricole, il est décrit par l'éducateur comme dépassé par la situation. Sa mère est dite " enfermée dans sa culture ».

Lamine est né en Tunisie. Il appartient à une fratrie de deux pères différents. Son géniteur est venu s'installer en France avec toute sa famille puis est rentré, seul. La mère finira par s'installer avec le grand-père de Lamine qu'elle considère comme le chef de famille.

L'homme qui a reconnu Amary à la naissance a entamé une procédure de désaveu en paternité alors qu'il avait 15 ans. Le couple s'était séparé lorsqu'il avait 13 ans et il a été hébergé avec ses frères et sa mère dans une structure d'aide. Sa mère vit depuis quelques années avec un autre homme. 


\section{Contrôle familial de la déviance et faiblesse de l'intégration normative} seulement suite aux processus d'ajustement internes à la famille, mais vis-à-vis de l'extérieur, de ce qu'est une société juste. Car les deux choses sont liées : la discussion de ce qui est juste dans la sphère privée amène à relativiser l'ordre social qui ne va plus de soi. D'autant quand les parents sont critiqués par leurs enfants pour avoir accepté eux-mêmes un ordre social inégalitaire, l'exploitation dans le travail, de s'être soumis ${ }^{47}$. La troisième source de relativisation des principes de justice provenant d'une comparaison entre les incivilités et les délits que peuvent commettre les jeunes ou leurs pairs et ceux des hommes politiques, des violeurs ${ }^{48}$ ainsi qu'en référence aux discriminations qu'ils subissent. Dès lors les injonctions des parents à respecter les règles, à « jouer le jeu » (entre autres de l'investissement scolaire), à être honnête sont disqualifiées. journal local, en fournit une illustration : « Un homme âgé de 31 ans a été condamné à 4 ans de prison avec sursis hier par la cour d'assises du Tarn pour avoir, en mai 2000, infligé à son petit frère de 14 ans une correction qui avait entraîné le décès de l'adolescent. L'adolescent de 14 ans, un enfant instable, vivait avec sa sœur et son frère aîné. Dans la nuit du 30 avril au $1^{\mathrm{er}}$ mai, il s'était rendu à une fête de quartier puis était sorti dormir chez un copain, sans prévenir son frère et sa sœur. Le lendemain, ces derniers étaient partis le chercher avec l'intention de le ramener au domicile familial. L'adolescent avait refusé de discuter avec son frère, se contentant de l'insulter. Ce 
dernier l'avait alors frappé à deux reprises. L'adolescent était tombé, inconscient. Transporté à l'hôpital, il était mort » (Journal La Dépêche).

On trouve d'abord dans cette histoire le facteur structurel : la composition de la famille. Qui élève qui, quelle est la circonférence de la famille? On trouve en outre un élément supplémentaire au désaccord sur les normes : quels sont les « bons » moyens pour faire accepter une norme - ici la norme qui veut qu'un enfant de 14 ans ne puisse découcher sans prévenir. Bons signifiants efficaces : acceptables par le jeune, produisant les effets recherchés. Inefficaces sont les règles énoncées par des aînés déconsidérés ou qui commettent eux-mêmes des délits. Inefficaces peut être l'usage de la contrainte et de la punition physiques que le jeune considère illégitimes.

Pour que des injonctions soient efficaces, que des règles soient suivies, il faut que celui qui les émet soit légitime. Or d'autres sources d'illégitimation proviennent de la comparaison du modèle éducatif dont les jeunes font l'expérience avec celui qu'ils perçoivent chez leurs pairs, qu'ils observent dans les fictions, les séries télévisées ainsi que sa condamnation, en certains cas, par les professionnels de l'Éducation nationale et du travail social. La relation entre membres de la famille est médiée par l'État, ses institutions, ses représentants. La question "qui éduque les enfants?» est une question que (se) posent les parents - les enfants au plus jeune âge - qui ne comprennent pas l'immixtion des professionnels dans leurs manières de faire, leur définition de la bonne éducation ${ }^{49}$. Quel que soit le style éducatif employé, celui-ci doit être soutenu, encouragé, reconnu par le système culturel global dans lequel il s'inscrit. L'injonction faite aux «beurettes" à s'émanciper de l'emprise conçue comme rétrograde d'un milieu paternaliste et oppressif ne fait par exemple qu'exacerber le dilemme et représente un cas de cette disjonction entre un modèle éducatif particulier - qui pour l'essentiel se cherche - et un modèle supposé valable pour tous. Les «beurettes » sont perçues comme des jeunes filles opprimées qu'il faut sauver de ce milieu familial et culturel ${ }^{50}$.

Il est tout à fait fréquent d'entendre sur les quartiers de relégation des travailleurs sociaux ou des «psy»(psychologues, psychiatres, rééducateurs...) condamner des moyens utilisés par des parents pour se faire respecter. Ces moyens ne sont pas condamnés parce qu'inefficaces mais parce que moralement condamnables. Ils sont jugés culturellement inadéquats, en référence à ce qu'est la norme culturelle en France ${ }^{51}$.

61 Un autre exemple nous permettra d'avancer sur ce qui peut se produire comme conflit de culture et modèle éducatif dans la sphère privée. Un jeune adulte ${ }^{52}$ nous dit : « Il y a une histoire, j'oublierai pas c'était parce que j'avais séché en cours. L'assistante sociale du collège elle est venue chez moi pour dire que j'avais manqué trois jours. C'était pas vrai : j'avais manqué une heure chaque jour [...]. Et mon père pour se laver vis-à-vis de cette femme il m'a giflé devant elle. Je lui ai dit papa elle a menti. Il m'a pas cru. Il m'a dit, elle peut pas mentir ». L'assistante sociale incarne l'intrusion de l'État dans la sphère privée. Mais elle cristallise aussi ici les conflits de culture que peuvent expérimenter les membres de la famille.

62 Au total, ce n'est pas d'une ignorance des règles dont il s'agit - qui ne peut concerner en réalité que les seuls arrivants - mais de leur faible intégration. On les connaît sans les reconnaître. Au total, c'est moins la distance culturelle qui compte que l'absence de cohésion communautaire, comme l'avaient déjà montré les chercheurs de l'École de Chicago et comme le note également Sellin citant un auteur pour qui « un groupe bien 
organisé, quoique d'une culture différente, engendre chez ses membres une plus grande conformité que ne le font les groupes désorganisés et de cultures hétérogènes " (1984: 92).

63 Il n'était pas question dans cet article de reprendre les thèses de Sellin sans les aménager, d'autant que même s'il n'est pas suspect de culturalisme, les théories contemporaines de l'ethnicité permettent de faire évoluer ses idées en accentuant la dimension relationnelle et subjective des conflits de culture. Sellin par ailleurs se limitait aux normes et valeurs qui ont été sacralisées par la loi, au rapport entre conflit de culture et crime.

Nous avons tenté d'articuler ici non seulement les dimensions objective et subjective des conflits culturels mais aussi les conditions sociales, spatiales de leur émergence.

Les conflits de culture sont un phénomène normal des sociétés modernes, a fortiori multiculturelles. Ce n'est qu'une des figures des nombreux conflits entre groupes sociaux que connaissent toute société. Leurs effets sur la cohésion sociale ne sont pas nécessairement délétères. Ils aboutissent au contraire à constituer et légitimer un ordre social, des hiérarchies : minoritaire vs majoritaire, civilisé vs sauvage, moderne vs traditionnel, universel vs particulier. Nous avons vu que la régulation de ces conflits peut être envisagée au niveau de l'État et de la législation, par le rejet des cultures minoritaires au nom de l'universel ou en attribuant une place à la diversité. Les travaux de Sellin sont fondés sur l'idée qu'en traduisant dans la loi des préférences culturelles, un État peut criminaliser des croyances, des pratiques, des valeurs.

$\mathrm{Au}$ niveau individuel, les effets de ces conflits de culture peuvent se traduire de différentes manières. Engagés dans un conflit de culture, les jeunes peuvent trouver les ressources personnelles ou institutionnelles pour faire face, concilier, aménager, négocier leur appartenance culturelle. Ils peuvent extérioriser les conflits vécus soit par des comportements déviants, soit par des revendications politiques. Ils peuvent encore les intérioriser. Les pratiques à risque, les pathologies, les souffrances, les délits... sont autant de réactions à des conflits culturels. Comment isoler la délinquance et ne pas mettre en parallèle les délits commis, les incivilités, les émeutes et le nombre considérables d'échecs scolaires, d'orientation des enfants d'origine étrangère des quartiers de relégation vers le secteur de l'enfance inadaptée, le surencombrement des structures psychiatriques, associatives ou publiques? Car la question des conflits de culture se joue sur ces différentes scènes. À trop se focaliser sur les délits, on laisse dans l'ombre les autres conséquences possibles, pour les jeunes, de ces conflits.

Pour le sociologue, les conflits de culture peuvent aussi bien être analysés comme une cause de comportements déviants - déscolarisation, suicide, pratiques à risque... - que comme l'interprétation que les professionnels choisissent de donner à ces comportements. Dans une perspective interactionniste cette fois, on peut remarquer que la centration sur les délits ignore les processus par lesquels les acteurs sociaux, les adultes, les professionnels de l'éducation, du travail social, attribuent un sens plutôt qu'un autre aux déviances des jeunes d'origine étrangère. En isolant la délinquance, on tient pour acquis ce qui est une construction de sens. Or on peut faire l'hypothèse que lorsque les acteurs sociaux et particulièrement les professionnels qui interviennent sur les quartiers de relégation interprètent un comportement comme déviant plutôt que normal, qu'ils le considèrent comme relevant de la pédagogie ou de l'insertion, de la rééducation ou de la psychopathologie, ils prennent en compte, d'une certaine manière, l'origine culturelle des jeunes. 


\section{BIBLIOGRAPHIE}

AEBI Marcello (2005) «Immigration et délinquance : le mythe du conflit de cultures », in Nicolas QUELOZ et. al. Éd., Délinquance des jeunes et justice des mineurs. Les défis des migrations et de la pluralité ethnique, Berne \& Bruxelles, Staempfli Éditions \& Bruylandt, pp. 97-124.

ALAMARTINE Françoise (2003) « À propos de "manifestations ethniques" dans un LP parisien », in Françoise LORCERIE Dir., L'école et le défi ethnique. Éducation et intégration, INRP, pp. 101-114.

AZZI Assaad (1994) «La dynamique des conflits intergroupes et les modes de résolution de conflits », in Richard BOURHIS, Jacques-Philippe LEYENS Éds., Stéréotypes, discrimination et relations intergroupes, Liège, Mardaga, pp. 293-319.

BASTENIER Albert (2004) Qu'est-ce qu'une société ethnique ? Ethnicité et racisme dans les sociétés européennes d'immigration, PUF.

BAUER Alain, RAUFER Xavier (1998) Violences et insécurité urbaines, PUF, Coll. QSJ.

BEAUD Stéphane, PIALOUX Michel (2002) «Sur la genèse sociale des "émeutes urbaines " ", Sociétés contemporaines, 45-46, pp. 215-243.

BERNARDET Philippe (1998) Étude du rapport justice-psychiatrie dans la prise en charge de la jeunesse en difficulté, originaire des régions de l'Afrique subsaharienne, Paris, GIP « Mission de Recherche Droit et Justice ».

BECKER Howard (1985) Outsiders, Métailié.

BORDET Joëlle (2001) «Les microsociétés des jeunes dans les quartiers d'habitat social. Débats contemporains », Revue Européenne des Migrations Internationales, vol. 17, n² 2, pp. 169-174.

BORN Michel (2005) « Violences exercées sur les jeunes filles dans les familles d'origine étrangère ", in Nicolas Quéloz et. al. Éd., Délinquance des jeunes et justice des mineurs. Les défis des migrations et de la pluralité ethnique, Berne \& Bruxelles, Staempfli Éditions \& Bruylandt, pp. 35-44.

BRION Fabienne, TULKENS Françoise. (1998) « Conflit de culture et délinquance. Interroger l'évidence ", Déviance et société, vol. 22, n³, pp. 235-262.

CAMILLERI Carmel et COHEN-EMERIQUE Margalit Dir. (1989) Chocs de cultures : concepts et enjeux pratiques de l'interculturel, L'Harmattan.

CAMILLERI Carmel et. al. (1990) Stratégies identitaires, PUF.

COSTA-LASCOUX Jacqueline (2001) « L'ethnicisation du lien social dans les banlieues françaises », Revue Européenne des Migrations Internationales, vol. 17, $\mathrm{n}^{\circ}$ 2, pp. 123-138.

DEBARBIEUX Éric et TICHIT Laurent (1997) « Le construit «ethnique» de la violence », in Bernard CHARLOT, Jean-Claude EMIN Dir., Violences à l'école, État des savoirs, Armand Colin, pp. 155-177.

DEBARBIEUX Éric (2003) « Au collège. L'effet de l'organisation scolaire », in Françoise Lorcerie Dir. (2003) L'école et le défi ethnique. Éducation et intégration, INRP, pp. 139-145.

DELCROIX Catherine (1995) Une nouvelle approche de la prévention de la délinquance des jeunes maghrébins : le rôle social des pères, Paris, Études de l'ADRI.

DELCROIX Catherine (1996) «Immigration : histoires et mémoires », Informations sociales, 56, pp. 96-106. 
DELCROIX Catherine (1999) «Les parents des cités : la prévention des risques encourus par les enfants », Annales de la recherche urbaine, 83-84, pp. 97-106.

DE RUDDER Véronique, POIRET Christian, VOURC'H François (2000) L'inégalité raciste : l'universalité républicaine à l'épreuve, PUF.

DOUVILLE Olivier, GALAP Jean (1999) « Santé mentale des migrants et des réfugiés en France », Encyclopédie médico-chirurgicale, Psychiatrie, Elsevier.

GUENIF-SOUILAMAS Nacira (2003) « Les “beurettes" aujourd'hui », in Françoise Lorcerie Dir (2003) L'école et le défi ethnique. Éducation et intégration, INRP, pp. 153-159.

GUENIF-SOUILAMAS Nacira, MACE Éric (2004) Les féministes et le garçon arabe, Éditions de l'Aube.

HAJJAT Abdellali (2005) Immigration postcoloniale et mémoire, L'Harmattan.

GUIMOND Serge, TOUGAS François (1994) « Sentiments d'injustice et actions collectives : la privation relative ", in Richard BOURHIS, Jacques-Philippe LEYENS Éds., Stéréotypes, discrimination et relations intergroupes, Liège, Mardaga, pp. 201-232.

HAMMOUCHE Abdelhafid (1997) «Famille relationnelle en situation migratoire, autorité paternelle et puissance publique », Lien social et politique-RIAC, 37, pp. 121-132.

HILY Marie-Antoinette, POUTIGNAT Philippe (1998) « La famille maghrébine entre visibilité et invisibilité : variations selon les contextes locaux », Revue Européenne des Migrations Internationales, vol. $14, \mathrm{n}^{\circ} 3$, pp. $7-26$.

KELLERHALS Jean, VALENTE Luicila (1986) «Interactions familiales et styles de contrôle de la déviance ", Déviance et société, n 10, 4, pp. 341-361.

JUTEAU Danielle (1999) L'ethnicité et ses frontières, Les presses de l'université de Montréal.

KAËS René Dir. (1998) Différence culturelle et souffrances de l'identité, Dunod.

KHOSROKHAVAR Farhad, DUPREZ Dominique, MUCCHIELLI Laurent (2000) « La violence et ses avatars dans les quartiers sensibles. Les désordres urbains : regards sociologiques ", Déviance et société, vol. $24 \mathrm{n}^{\circ}$ 4, pp. 425-440.

KHOSROKHAVAR Farhad (1997) L'islam des jeunes, Flammarion.

KOKOREFF Michel (2003) La force des quartiers. De la délinquance à l'engagement politique, Payot.

LAGRANGE Hugues (2001) De l'affrontement à l'esquive. Violences, délinquances et usages de drogues, Syros.

LAPEYRONNIE Didier (1987) « Assimilation, mobilisation et action collective chez les jeunes de la seconde génération de l'immigration maghrébine », Revue française de sociologie, XXVIII, pp. 287-318.

LESSING Théodor (1990) La haine de soi. Le refus d'être juif, Paris Berg international, (1930 pour l'ed. or.)

LORCERIE Françoise (1994) « Les sciences sociales au service de l'identité nationale. Le débat sur l'intégration en France au début des années 1990 », in MARTIN Denis-Constant Dir. Cartes d'identité. Comment dit-on «nous » en politique ?, FNSP, pp. 245-282.

LORCERIE Françoise Dir. (2003) L'école et le défi ethnique. Éducation et intégration, INRP.

MALEWSKA-PEYRE Hanna (1982) Crise d'identité et déviance chez les jeunes immigrés, Vaucresson, CFRES. 
MANÇO Altay (1999) Intégration et identités. Stratégies et positions des jeunes issus de l'immigration, Bruxelles, De Bœck.

MUCCHIELLI Laurent (2000) «Familles et délinquances. Un bilan des recherches francophones et anglophones », Dossier d'Étude, n 9, CNAF.

MUCCHIELLI Laurent (2003) « Délinquance et immigration en France : un regard sociologique », Criminologie, vol. $36, \mathrm{n}^{\circ}$ 2, pp. 27-55.

PAYET Jean-Paul., VAN ZANTEN Agnès (1996) «L'école, les enfants de l'immigration et des minorités ethniques », Revue française de pédagogie, n 117, pp. 87-149.

PETEK-SALOM Gaye (1999) « La difficile intégration des immigrés de Turquie » in P. Dewitte (dir) Immigration et intégration. L'état des savoirs, La découverte, pp. 149-154.

POIRET Christian (2003) «Criminalisation de l'immigration et sociologie des relations interethniques », Hommes et migrations, n 1241, pp. 6-19.

POUTIGNAT Philippe, STREIFF-FENART Jocelyne (1995) Théories de l'ethnicité, PUF.

REA Andrea (2001) «Délinquance et immigration : usage politique d'une association symbolique », in Albert Bastenier Dir., Mon délit? Mon origine, De Bœeck, pp. 39-76.

ROBERT Philippe (1999) « Le sociologue, la culture et le crime », in Jean-Michel Bessette Éd., Crimes et cultures, L’Harmattan, pp. 29-59.

ROBERT Philippe (2005) La sociologie du crime, La découverte, Coll. Repères.

ROY Olivier (1993) «Les immigrés dans la ville. Peut-on parler de tensions ethniques ? », in Joël ROMAN Dir. Ville, Exclusion, citoyenneté, Éd. Esprit, pp. 117-131.

SAYAD Abdelmalek (1994) « Le mode de génération des générations “immigrées" ", L'homme et la société, $\mathrm{n}^{\circ} 111-112$.

SELLIN Thornstein (1960) «Conflits culturels et criminalité », Revue de droit pénal et de criminologie, $\mathrm{n}^{\circ}$ 9, juin, pp. 815-833.

SELLIN Thornstein (1984) Conflits de culture et criminalité, Éd. Pédone (Trad. fr. de Culture conflict and crime, New York, Social science research Council, 1938).

SICOT François (2000) « Enfants d'immigrés maghrébins : rapport au quartier et engagement dans la délinquance ", Les Cahiers de la sécurité intérieure, $n^{\circ} 42$, pp. 87-108.

SICOT François (2003) « Quelle transmission culturelle pour les jeunes des quartiers de relégation? », EMPAN, $\mathrm{n}^{\circ} 50$, pp. 38-44.

SICOT François (2005) « Les CER, un placement (pénal) parmi d'autres ? », EMPAN, nº 59, pp. 91-104.

SPITZ Jean-Fabien (2005) « Difficultés d'ajustement et injonction paradoxales dans l'intervention psychosociale auprès des jeunes immigrés d'Afrique centrale ", in Nicolas Quéloz et. al. Éds., Délinquance des jeunes et justice des mineurs. Les défis des migrations et de la pluralité ethnique, Berne \& Bruxelles, Staempfli Éditions \& Bruylandt, pp. 449-460.

TABOADA-LEONETTI Isabel (1990) Stratégies identitaires, PUF.

TAGUIEFF Pierre-André (1991) « Les métamorphoses idéologiques du racisme et la crise de l'antiracisme » in Pierre-André TAGUIEFF Dir. Face au racisme, tome II, La découverte, pp. 13-63.

TARRIUS Alain (2001) «Au-delà des États-nations : des sociétés de migrants », Revue Européenne des Migrations Internationales, vol. 17, $\mathrm{n}^{\circ}$ 2, pp. 37-62. 
TODD Emmanuel (1994) Le destin des immigrés. Assimilation et ségrégation dans les démocraties occidentales, Le Seuil.

VILLECHAISE Agnès (1997) « La banlieue sans qualités. Absence d'identité collective dans les grands ensembles », Revue française de sociologie, XXXVIII, pp. 351-374.

VINSONNEAU Geneviève (1996), L'identité des jeunes en situation inégalitaire. Le cas des Maghrébins en France, L'Harmattan.

WIRTH Louis (1931) «Culture conflict and Delinquency I. Culture conflict andmisconduct », Social forces, vol. $9, \mathrm{n}^{\circ} 4$, pp. 484-492.

WITHOL DE WENDEN Catherine (1999) «Les «jeunes issus de l'immigration» entre intégration culturelle et exclusion sociale », in Philippe DEWITTE Dir. Immigration et intégration. L'état des savoirs, La découverte, pp. 232-237.

YAHYAOUI Abdessalem Dir. (1998) De la place du père, La pensée sauvage.

\section{NOTES}

1. Évidemment des sociologues travaillent sur la question ethnique depuis de nombreuses années en France. Mais à fois au regard de ce qui se fait dans les pays anglo-saxons et de la place de l'ethnicité à côté du genre, de l'âge ou du milieu social dans les rapports sociaux, il y a une faiblesse patente de ce domaine de recherche.

2. Voir Mucchielli, 2003 ; Brion, 1998; Aebi, 2005. On verra qu'il s'agit de ne pas confondre l'existence de conflits de culture et le fait d'attribuer la surdélinquance des étrangers ou de leurs enfants à des différences culturelles.

3. Rappelons que l'on distingue classiquement les recherches qui portent sur le passage à l'acte, l'explication de la déviance, qui tentent de répondre à la question du pourquoi ; et les recherches qui portent sur la réaction sociale, à partir de l'idée que « le caractère déviant ou non d'un acte dépend de la manière dont les autres réagissent (...). La déviance est une propriété non du comportement lui-même, mais de l'interaction entre la personne qui commet l'acte, et celles qui réagissent à cet acte » (Becker, $1985: 35)$.

4. L'archétype étant en France l'ouvrage de Bauer et Raufer, 1998. Pour une lecture critique de ce livre ; Mucchielli sur le site internet CLARIS.

5. Sur l'école et la question de l'immigration ; Payet, Van Zanten, 1996. Les analyses ont toutefois notablement évolué ces dernières années grâce en particulier aux travaux de J.P. Payet, 1996 ; F. Lorcerie, 2003 ; E. Debarbieux, 2003.

6. On retrouve cette idée, mot pour mot, chez de nombreux auteurs dont Villechaise, 1997 ; Roy, 1993 ; Muccchielli, 1999; Kokoreff, 2003 ; Lapeyronnie, 1987. Un exemple de ce volontarisme intégrationniste est donné avec C. Withol de Wenden. Elle titre ainsi un article : «Les "jeunes issus de l'immigration", entre intégration culturelle et exclusion sociale » (in Dewitte, 1999), dont l'objectif est clairement de contrer les représentations négatives, stigmatisantes des jeunes d'origine maghrébine - les jeunes issus d'autres immigrations étant dès lors oubliés. "Si l'imaginaire social stigmatise la délinquance, les violences, les incivilités ou l'islam militant, l'intégration socioculturelle progresse, en décalage avec l'insertion économique » (236). Cette intégration socioculturelle consistant à participer à la «culture jeunes ». Le chômage fait pour l'auteur le berceau d'un "communautarisme instrumental qui tourne le dos à l'intégration » (236). s'opposant à un «imaginaire social exacerbé par la politique et les médias » qui ne cesse d'évoquer la non intégration, la dangerosité de ces jeunes. Cette auteure se focalise en fait 
d'enfants d'immigrés aux seuls Maghrébins et insiste sur leur bonne volonté - déçue d'intégration et leur appartenance à la « culture jeune ».

7. L'invisibilité de ces communautés tient sans doute à ce qu'ils ont trouvé les moyens d'affirmer leur identité discrètement.

8. Dans une enquête de délinquance auto-reportée (2001), H. Lagrange constate sans plus s'y attarder que « les adolescents issus de l'immigration européenne sont nettement surreprésentés dans ces catégories de conduite [violence expressive et prédations] alors que les Français dont les parents sont nés en France sont très sous-représentés ». Sont concernés essentiellement des jeunes d'origine portugaise.

9. Bastenier (2004) considère que le refus de la possibilité de prendre en compte l'existence de différences culturelles pour expliquer les phénomènes sociaux contemporains relève d'un «procès en hérésie culturaliste ».

10. C'est du moins l'effroi qui saisit le lecteur confronté aux condamnations prononcées par Taguieff envers ceux qui, préoccupés de la différence des identités culturelles, sont habités par «l'ambiguïté idéologique» et les «théorisations racistoïdes fondées sur le postulat de l'irréductibilité (...) des cultures » (Taguieff, 1991 : 33).

11. Participation qui s'est poursuivie au-delà de cette recherche.

12. Les jeunes filles d'origine maghrébine ont ainsi accédé à des paroles, ont appréhendé la question sous des angles, que des garçons d'autres quartiers ne pouvaient percevoir (Sicot, 2003). 13. Les murs sont graffités lors des moments de conflits de slogans tels que "Une seule race vaincrat. C'est les arabes; Ne laissons pas la police tués nos frères... "

14. Voir Camilleri, 1990; Malewska-Peyre, 1982; Manço, 1999; Taboada-Leonetti, 1990 ; Vinsonneau, 1996. Dans ses recherches sur le sujet, Malewska-Peyre montre bien le rôle de la perception précoce du racisme à l'école, dans les loisirs, dans la recherche de l'emploi, dans le rapport aux policiers. Elle souligne que les adolescents délinquants témoignent plus souvent que les autres d'un sentiment de dévalorisation et que, "dans des situations de blocage des possibilités sociales, la délinquance peut être considérée comme une stratégie revalorisante. [...] une sortie de l'impasse, une possibilité de «paraître», de devenir quelqu'un » (1997 : 18).

15. On n'en trouve pas mention dans les ouvrages présentant les sociologies de la déviance récemment parus à l'exception de Robert, 2005.

16. Le racisme étant indiscutablement un facteur de perception négative de soi et de son destin social qui peut alimenter l'entrée dans la délinquance.

17. Et aussi : «Il existe de nombreuses preuves que l'immigrant fait l'objet d'un traitement différent dans le processus d'administration du droit. Ceci est dû en partie à ses origines, en partie à sa situation économique et politique. Quelle que soit la raison, il y a plus de probabilité qu'il soit arrêté et condamné, et lorsqu'il est envoyé en prison, il est probable qu'il ira avec une peine plus forte que l'individu né dans le pays » (1938: 73).

18. C'est le cas en France avec la loi de 2003 réprimant l'occupation abusive des halls d'immeuble et de la loi de 2004 sur le port de signes religieux à l'école qui, de fait, concernent quasi exclusivement les jeunes d'origine maghrébine.

19. Sellin cite l'exemple de colonisation de l'Algérie par la France et la criminalisation de pratiques traditionnelles: "Chez les Kabyles d'Algérie, le meurtre des épouses adultères: meurtre rituel commis, non pas ainsi qu'ailleurs, par le mari, mais par le père ou le frère de l'épouse (...). Un magistrat français a pu parler de "la conspiration du silence chez les Algériens : conspiration qui a pour but de préserver les traditions, toujours suivies et obéies contre la mainmise de notre pouvoir" "(Sellin, $1938: 64-66$ ).

20. Un père de famille: "Là-bas au pays les commissions, c'est pas moi qui les monte, les escaliers, c'est des jeunes des quartiers qui viennent les prendre. Ici ça fait 6 ans... j'ai pas encore parlé avec un jeune, immigré ou autre, faudra... je ne leur ai jamais adressé la parole. J'ai vu comment ils font, comment ils parlent. Je ne veux pas leur parler seulement j'ai peur parce que je 
suis nerveux et si... il me fait seulement une grimace... C'est-à-dire que ça passe pas avec les jeunes. Je vois les jeunes d'Algérie - je dis d'Algérie parce que je suis algérien mais je pourrais dire au Maroc ou de Tunisie - là-bas ils ont une certaine culture, ils ne fument pas. Quand ils me voient arriver, disons jusqu'à 20 ans, ils se cachent. Ça c'est une tradition, du respect. Si je passe devant les jeunes c'est eux qui disent bonjour. Ici quand je vois comment ça parle, des gros mots, moi je les connais pas ». Malika : «Avec les voisines, chacune va chez l'autre. On se fait du thé, on parle des enfants surtout et de l'éducation qu'ils ont et que... et qu'ils s'éloignent un peu trop des valeurs on trouve ».

21. ... ou pour le dire autrement « ne veulent pas s'intégrer ».

22. Un jeune interviewé analyse ainsi l'évolution culturelle de sa sphère familiale : «à mon avis, tous les immigrés, les premiers immigrés, ils sont arrivés avec toute leur culture et toutes leurs habitudes, quoi. Et ça c'est resté, je pense que c'est resté longtemps comme ça en France. Après au fil des années, la culture, elle en prend un coup et les habitudes aussi, quoi. Tandis que moi, aujourd'hui, si j'y vais [au bled], je sais que je vais être dépaysé, quoi. Parce que, bien qu'il y ait un paquet de Maghrébins dans les cités, là, maintenant entre la culture de la cité, enfin, entre la culture maghrébine de cité et la culture maghrébine du pays, c'est plus pareil. Y a un gros changement là. Moi, là ça fait longtemps, ça fait neuf ans que j’y suis pas allé au bled ».

23. Il est d'ailleurs classique de considérer que le psychisme n'est jamais que de la culture intériorisée. La plus petite attention à la psychologie interculturelle ou à l'ethnopsychiatrie, de quelque obédience qu'elle soit, montre l'inanité d'une affirmation comme celle de «l'intégration culturelle » des enfants de migrants.

24. En insistant sur ce couple minoritaire/majoritaire et le rapport de domination qu'il implique, on se situe plus du côté de Juteau que de Bastenier pour qui « c'est le vécu d'une situation sociale commune en même temps que la conviction de participer à une tradition de valeurs culturelles particulières, réelles ou imaginaires, engendrant une orientation mutuelle des comportements et qui est la matrice de cette forme de communalisation qu'est l'appartenance ethnique » (2004 : 140).

25. C'est de manière exemplaire la thèse de Todd (1994) sur la fin des immigrés. Mais cette idée d'une pente naturelle qui fait disparaître les spécificités culturelles avec le temps se retrouve peu ou prou dans de nombreux travaux sur les immigrés.

26. Si l'observateur extérieur constate de visu que la très grande majorité des habitants sont d'origine étrangère, cela constitue un élément essentiel de l'expérience des jeunes. Hocine, 21 ans : « On peut pas essayer de s'identifier comme Français. Là... je sais pas mais c'est impossible. Même lorsqu'on part au parloir. Il suffit de voir qui est en prison. Au parloir j'y vais, je vois 50 collègues, les parents, les mères de famille avec leurs voiles. Il y a qu'à voir ça ». Chérif : « Il y a une famille de Français mais leurs enfants ne vivent plus ici. Ensuite dans tout l'immeuble il y a une femme avec ses chiens et puis c'est tout... J'ai un exemple personnel, je me rappelle de la première fois lorsque j'ai vu une blonde en réalité, je me rappelle c'était en CM2. Et ça j'oublierai jamais parce qu'on est parti avec une école primaire de $\mathrm{X}$, ils étaient déjà dans le bus, ils sont venus nous chercher, et on voit des blondes. On en avait vu qu'à la télé. On était tous là, excités (...). Quand je réfléchis bien c'est grave quand même. On vit là pratiquement de 0 à 12 ans on vit là, on se forge notre comportement ici, entre nous. Et c'est là que ça coince plus tard ». Rachid ; «Le peu de Français qu'il y a souvent, je me rappelle de mon temps, le peu qui étaient avec nous à l'école primaire, ils déménageaient aussitôt. Même mes parents ce qu'ils me disaient c'est quand ils sont venus emménager ici en 78, leurs voisins c'étaient pratiquement que des Européens. Progressivement, au fur et à mesure que les familles étrangères arrivaient ils sont partis ». Fatima, mère de quatre enfants : «Quand je suis arrivée sur le quartier, j'avais l'impression d'être en Algérie. C'est ma première impression, je me suis sentie rassurée. C'est vrai que vivre avec des gens qui vous regardent de travers à longueur de journée [elle se réfère à l'extérieur du quartier] ça a quelque chose d'effrayant, c'est un combat de tous les jours. Disons que lorsqu'on se retrouve 
entre gens du même pays, ça a quelque chose de rassurant. Mais en même temps c'est pas bon. Moi mon souhait c'aurait été de vivre avec tout le monde, un échange avec toutes les communautés (...). Les enfants sont dans un collège on peut dire qu'il y a sans exagérer $80 \%$ de Maghrébins. Je me suis dit, qu'est-ce qu'ils peuvent apprendre de l'autre ? C'est pas possible». Khader, 26 ans : «Au collège ils nous déconseillaient fortement d'aller en seconde générale parce que c'était dur et ils nous disaient qu'on avait pas la même culture que les autres. - Quand tu parles de culture tu fais référence à quoi ? - Culture générale et ils avaient à moitié raison parce que quand je suis arrivé au lycée dans les matières scientifiques j'étais très fort mais par contre en français...j'ai appris à parler en français au lycée. Avant je savais pas »...

27. L'Arabe constituant la figure paradigmatique de l'étranger, celui qui concentre tous ses défauts.

28. Miloud: «Tu sais mes parents ils étaient tellement dans la misère en Algérie, ici tu leur faisais ramasser de la merde, ils la ramassaient. Mais nous ça c'est une chose qu'on fera pas. Quand je dis nous, c'est les types qui ont des parents qui sont morts ou malades à cause de l'exploitation qu'ils ont dû subir pour avoir de quoi nourrir leur famille. Je préfère voler, vendre de la drogue que de subir ça. Même si c'est mauvais ce que je dis ».

29. Sous-entendu des Français nés de parents français qui constitueraient dès lors la norme permettant de déclarer qu'il y a ou non différence. Car à trop vouloir montrer qu'ils sont comme les autres - sinon plus pauvres et discriminés - on postule peut-être l'existence de quelque chose comme une identité française, qui plus est érigée en norme permettant de dire l'identité ou la différence.

30. Occasion de vivre le conflit de culture quand on s'entend demander ou qu'on se demande soimême : Marocain ou Français?

31. En cela nous sommes pleinement en accord avec Bastenier pour qui « le recours à l'argument ethnique ne saurait, sans plus être assimilé à une réaction de frustration vis-à-vis d'une aspiration bloquée à la mobilité sociale ascendante » $(2004: 112)$.

32. Dans deux immeubles leur proportion est de $62 \%$ et $67 \%$ !

33. Sur la répartition de populations dans les quartiers sur des bases ethniques comme sur les diverses occurrences de cohabitation de populations d'origine différentes, voir les travaux de Rudder et. al., 2000.

34. Hypothèse concurrencée comme il se doit pas l'affirmation que si les jeunes sont dehors c'est d'abord parce que les appartements sont trop exigus.

35. Néanmoins, on sait l'effort de discrétion et la volonté d'invisibilisation par lesquelles nombres de parents Maghrébins ont conçu leur présence voire leur intégration en France. Pratiques que leurs enfants ont rapidement pu considérer comme insupportables. Parmi beaucoup d'autres, ce témoignage l'illustre : «Comment ça se passait quand tu étais petit ?- Eh ben, ma mère était toujours à la maison. Déjà, à l'époque ils faisaient très attention à nous, quoi, et je me souviens que dépassé sept heures du soir, il fallait être à la maison. Voilà, ça c'est les faits marquants, pour moi, c'était ça, parce que je trouvais que c'était sévère. D'un côté, je me dis qu'ils voulaient préserver leurs enfants et tout ça, quoi mais, de l'autre côté, quand je voyais

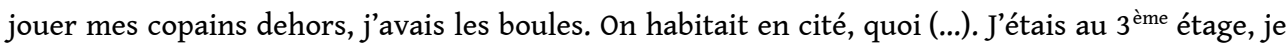
voyais mes copains dans la rue et moi, j'étais à la maison. À partir de 8 heures, 8 heures et demi, il fallait fermer les volets, et que là, ça y est, quoi. C'était au lit. Ouais, on dirait, pour la plupart des enfants, ça se passe ainsi, mais pas en vie en cité, on a tous ses copains, il y a un petit système qui se met en place et quand on est écarté de ce système, on a un peu les boules ».

36. Pour certaines des formes de ces conflits de culture, les psychologues parleraient d'ambivalence.

37. Extraits d'entretiens: «Ce qui est bien avec une double identité, c'est le fait de pouvoirchoisirce qu'il y a de bien dans les deux pays "; "J'y tiens à ma culture, et je tiens à certaines choses qui sont bien là-bas, mais il y a beaucoup de choses qui sont bien ici. En fait, tu 
te fais ta propre culture »; "Si tu veux l'Algérie, c'est mes racines, ma culture, ma fierté. Mais mon caractère vient du fait d'avoir vécu en France et donc d'avoir été à l'école avec des Blacks, des Arabes, des Français, des Asiatiques »; «L'adolescence c'est l'âge où tu te renies, t'as envie de ressembler aux filles des magazines. Tu te raidis les cheveux... et tes parents ils sont exaspérés de te voir comme ça $" . .$.

38. Pour les filles, voir aussi Khosrokhavar, 1997.

39. Cette recherche relève également l'importance de la dynamique migratoire. Il faut ainsi distinguer « les violences subies par les jeunes filles socialisées en France qui se distinguent des violences subies par les jeunes femmes arrivées par le regroupement familial » (Born, 2005 : 39).

40. Avec en particulier ce que Hajjat nomme après Memmi et d'autres la « haine de soi » qui «découle du conflit non résolu entre l'intériorisation d'une représentation négative de soi véhiculée par la culture dominante et la volonté inassouvie d'exprimer une identité positive » (2005 : 85). Sur cette notion ; Lessing, 1990.

41. Voir Azzi, 1994 ; Guimond, Tougas, 1994.

42. Ce sont des attitudes exclusivement paternelles.

43. Entretien avec un père, 59 ans, algérien: "Vous avez conservé le rôle du père, de celui qui pose les limites? Oui mais ils écoutent plus, c'est à cause du milieu - Vous pensez que si vous étiez restés en Algérie, vos rapports auraient été différents? - Ah oui, mais c'est pour leur bien quand on leur dit des choses. Quand ma fille elle prend le métro, à huit heures du soir même j'ai peur (...). Mais pas pour mon garçon, je m'en fous du garçon, je lui ai dit : il y a même pas trois jours ; tu viens pas j'en ai rien à foutre, mais la fille non il faut la protéger... ».

44. À l'exception notable au moins des travaux de C. Delcroix, 1996 ; 1999.

45. Une organisation familiale est fonctionnelle dans un contexte. Il suffit de penser à l'inefficacité d'un contrôle social des enfants reposant sur la famille élargie ou la communauté dans le contexte urbain français. Voir par exemple Bernardet, 1998.

46. L'incertitude quant aux valeurs à transmettre provient en partie également de l'incertitude sur ce que doit être l'intégration des enfants et ce qui est le mieux à même de la permettre et, plus récemment des doutes quant à l'avenir possible en France. Comment faire le pari de l'assimilation, de la mort en soi de sa culture, quand on n'est pas sûr de pouvoir rester?

47. Medhi, 23 ans : «La majorité qui se sentait agressée c'était des Algériens - Pourquoi ? - Bah justement par rapport à la guerre d'Algérie. Nos parents nous en ont parlé, quand on était plus jeunes. Ils nous disaient voilà ce qu'on subissait. Et nous on se disait, bordel, comment ça se fait, qu'on ait traité nos grands-parents et nos parents de cette façon. Étant donné qu'on est chez nous, on va faire en sorte que ça se reproduise pas, ou alors on leur fera payer. Bon, on réagissait vraiment bêtement ». Miloud, 29 ans : «Tu sais, mon père, mes parents, ils étaient tellement dans la misère en Algérie, ici tu leur faisais ramasser de la merde, ils la ramassaient. Mais nous ça c'est une chose qu'on fera pas. Quand je dis nous, c'est les types qui ont des parents qui sont morts ou malades à cause de l'exploitation qu'ils ont dû subir pour avoir de quoi nourrir leur famille ».

48. Dans ces comparaisons, le caractère véniel de leurs actes est souvent rapporté aux actes des violeurs et autres pédophiles.

49. Entretien avec un jeune père, à propos des voitures brûlées : «Mais Monsieur ça se sont des phénomènes que le père il peut rien pour son fils. Vous Monsieur, votre femme elle décide de divorcer, qu'est-ce que vous pouvez faire? Moi mon fils il brûle des voitures, qu'est-ce que je fais, je le tue? Chez nous c'est les voitures qui brûlent, chez vous c'est le divorce. Vos femmes vous pouvez pas les tenir? Nous c'est nos fils. Les parents ils peuvent rien. Mon fils il est jeune. Je le tiens. À huit heures du soir il est à la maison. Mais à 15-16 ans je peux pas le tenir ? Je peux vous dire comment ça se passe. Mon fils à huit heures il sort avec ses copains. Il est dehors. L'influence, le cinéma, Taxi 1, Taxi 2, à la télé un éduc a été agressé, patati patata... Si il brûle une voiture un jour, il va pas me faire un rapport. Un jour je vais être convoqué au commissariat. Concernant votre fils, on a attrapé une bande, il y a votre fils. Mais moi Monsieur mon fils il fait 
pas de bêtises ?! Déjà entre le père et le fils il y a un monde. Il a brûlé une voiture ou cassé un magasin. Je l'attrape ? Il me dit c'est pas moi, je te jure, ils ont menti... OK ça passe. Jusqu'au jour où il prend un an ferme. Voilà. C'est comme ça que ça se passe ".

50. Voir aussi, sur cette injonction à se libérer - selon un modèle bien précis de ce qu'est une femme libérée - Guénif-Souilamas, Macé, 2004.

51. Évidemment, c'est la norme que soutiennent ces professionnels ici et maintenant. «En Afrique, les châtiments corporels, les privations de nourriture et de sortie, la honte infligée au jeune déviant sont des méthodes éducatives ayant une légitimité, leur vertu pédagogique est clairement reconnue. Ces pratiques sont pour les parents africains la meilleure façon de témoigner de leur rôle parental et ne pas les utiliser est faire preuve de lâcheté. Dans notre société occidentale, ces mêmes pratiques n'ont pas cette légitimité dans l'éducation, mais sont, au contraire, identifiées comme de la maltraitance physique et psychologique » (Spitz, 2005 : 454).

52. Désormais bien souvent, les jeunes dont il est question ne sont plus de la «deuxième génération » mais sont les petits-enfants des immigrés arrivés dans les années soixante.

\section{RÉSUMÉS}

Deux thèses s'opposent apparemment à propos de la délinquance des jeunes des banlieues ; celle, politique, qui impute leurs comportements à leur culture ou à leur impossibilité à s'intégrer et celle, sociologique, qui affirme leur intégration culturelle mais pointe, parmi les facteurs explicatifs, la non intégration économique, les discriminations, la criminalisation opérée par le travail de la justice et de la police. Nous voudrions montrer ici l'intérêt de ne pas se limiter à la question des discriminations et considérer en quel sens la culture pourrait intervenir dans l'explication du phénomène. Renouvelée par les théories contemporaines de l'ethnicité, la «théorie des conflits de culture» permet de concevoir le sens des déviances des jeunes des minorités reléguées sans leur attribuer pour autant une culture inadaptée.

Young People from the Suburbs, Culture Conflicts and Deviant Behaviors. Two different points of view try to explain youth delinquency in urban suburbs. On one side, we have a political interpretation which focuses on the importance of culture as a major obstacle for integration of the youth. On the other side, sociologists tend to acknowledge their cultural integration while underlying the economic difficulties and the discriminations they pass through and the criminalization of their acts by Justice and police treatment. This paper points out the limits of considering only the discrimination point of view and tries to value the cultural variable as an important explaining factor. Recent studies in ethnic relations show how the Sellin's theory of "conflict culture" should be overcome making place for a "conflict of cultures" position : in this way, it is possible to understand deeply the meaning of youth delinquency when generated by minorities marginalized in urban suburbs.

Conflicto de cultura y desviación de los jóvenes de los suburbios. Aparentemente, dos tesis se enfrentan en una oposición respecto a la delincuencia de jóvenes de suburbios. Una es de índole política, atribuye el comportamiento de estos jóvenes a su cultura o a la imposibilidad que tienen de integrarse. La otra, tesis sociológica, sostiene que su integración cultural es real, y que indica como factores de explicación de la delincuencia la ausencia de integración económica, las 
discriminaciones, la criminalización creada por el trabajo de la justicia y de la policía. Aquí deseamos demostrar, el interés a no limitarse solo al aspecto de las discriminaciones y también considerar de qué manera la cultura podría intervenir en la explicación de este fenómeno. Una nueva lectura de la «teoría de los conflictos de cultura", bajo el efecto de las teorías contemporáneas de la etnicidad, permite de concebir el sentido de las desviaciones de los jóvenes de minorías relegadas sin atribuirles para eso una cultura inadaptada.

\section{AUTEUR}

\section{FRANÇOIS SICOT}

Maître de conférences en sociologie, Université Toulouse II, CIRUS-Cers, Maison de la recherche, 5 Allées A. Machado, 31058 Cedex 9. 